\title{
A Glimmer of Hope: Maintain Mitochondrial Homeostasis to Mitigate Alzheimer's Disease
}

\author{
Wenbo Li ${ }^{1}$, Ling Kui², Tsirukis Demetrios ${ }^{3}$, Xun Gong ${ }^{4}$, Min Tang,6,* \\ ${ }^{1}$ State Key Laboratory of Natural and Biomimetic Drugs, School of Pharmaceutical Sciences, Peking \\ University, China. \\ ${ }^{2}$ Dana-Farber Cancer Institute, Harvard Medical School, United States \\ ${ }^{3}$ Boston Children's Hospital, Harvard Medical School, United States \\ ${ }^{4}$ Department of Rheumatology \& Immunology, The First Affiliated Hospital of Anhui Medical \\ University, China \\ ${ }^{5}$ Institute of Life Sciences, Jiangsu University, China \\ ${ }^{6}$ Center for Innovation in Brain Science, University of Arizona, United States
}

[Received October 19, 2019; Revised January 1, 2020; Accepted January 5, 2020]

\begin{abstract}
Mitochondria are classically known to be cellular energy producers. Given the high-energy demanding nature of neurons in the brain, it is essential that the mitochondrial pool remains healthy and provides a continuous and efficient supply of energy. However, mitochondrial dysfunction is inevitable in aging and neurodegenerative diseases. In Alzheimer's disease (AD), neurons experience unbalanced homeostasis like damaged mitochondrial biogenesis and defective mitophagy, with the latter promoting the disease-defining amyloid $\beta(A \beta)$ and $p$-Tau pathologies impaired mitophagy contributes to inflammation and the aggregation of $A \beta$ and $p$-Tau-containing neurotoxic proteins. Interventions that restore defective mitophagy may, therefore, alleviate AD symptoms, pointing out the possibility of a novel therapy. This review aims to illustrate mitochondrial biology with a focus on mitophagy and propose strategies to treat AD while maintaining mitochondrial homeostasis.
\end{abstract}

Key words: Alzheimer's disease, mitochondria dysfunction, mitophagy, $\mathrm{NAD}^{+}$

\section{Introduction}

Alzheimer's disease (AD) is the most frequent cause of dementia, affecting around 50 million individuals in 2018. By 2050, it will rise to 152 million [1]. AD prevalence is low among persons younger than 65 years, but increases to $10 \%$ to $30 \%$ among persons older than 85 [2-4]. Neuropathologically, the disease-defining histopathological abnormalities, including extracellular deposits of amyloid- $\beta$ (A $\beta$ ) peptide and intraneuronal accumulation of hyperphosphorylated tau (p-Tau), spread through the brain in a nonrandom manner with early pathology occurring in the entorhinal cortex and hippocampus [5-8]. Efforts made in AD research during the last several decades have provided essential insights into the pathogenesis of $\mathrm{AD}$, but the molecular mechanisms are not fully understanding recovered. Numerous standard and rare susceptibility AD-associated genes had found. Which can confer small etiologic origination [9-12]? Although AD was first discovered in

*Correspondence should be addressed to: Dr. Min Tang, Institute of Life Sciences, Jiangsu University, China. Email: mt3138@,ujs.edu.cn.

Copyright: ( 2020 Zhang F et al. This is an open-access article distributed under the terms of the Creative Commons Attribution License, which permits unrestricted use, distribution, and reproduction in any medium, provided the original author and source are credited. 
the late 19th century[13], an effective treatment has yet to develop. Moreover, there has not, however, been a pharmacological method created to fundamentally cure $\mathrm{AD}$, with mounting Anti-AD drugs 'dying' in phase III clinical trials [14].

Excluding the aggregate of $A \beta$ peptides extracellularly and microtubule-associated p-Tau intracellularly $[15,16]$, the $\mathrm{AD}$ research community increasingly believes that the accumulative damaged mitochondrial biogenesis in the brain mainly results from deficient mitochondrial autophagy (mitophagy), contributing a lot to $\mathrm{AD}$ pathogenesis [17, 18]. This review aims to discuss both the pivotal mammalian components of mitochondrial biology and aspects of mitophagy and the possible strategies to maintain mitochondrial homeostasis.

\section{Mitochondrial integrity and regulation}

\subsection{Mitochondrion in reasonable condition}

Mitochondria vary tremendously across cell types and tissues in morphology and allow for rapid changes in response to external lesions and metabolic prompts. Generally, there are multiple copies of mitochondria within cells, with diameters ranging from 0.75 and $3 \mathrm{um}$. However, all mitochondria are well known as the energy factories within various types of cells, employing the oxidative phosphorylation (OXPHOS) process to produce Adenosine triphosphate (ATP). The mitochondrion in most eukaryotic cells is a double-membrane-bound organelle comprised of a phospholipid bilayer. As Figure $1 \mathrm{~A}$ shows, it has an inner mitochondrial membrane (IMM) with numerous folded cristae, a smooth outer mitochondrial membrane (OMM) and the intermembrane space (IMS) between them. The mitochondrial morphology is dramatically shaped by ongoing fusion and fission (see Fig. 1B and 1C) on IMM and OMM [19, 20]. Beyond the IMM is the jelly-like matrix for respiration, where the breakdown of pyruvate into adenine triphosphate (ATP) and the tricarboxylic acid (TCA) cycle takes place $[21,22]$. Additionally, the electron transport chain (ETC) locates at the IMM, which is essential for the generation of ATP via oxidative phosphorylation machinery [23].

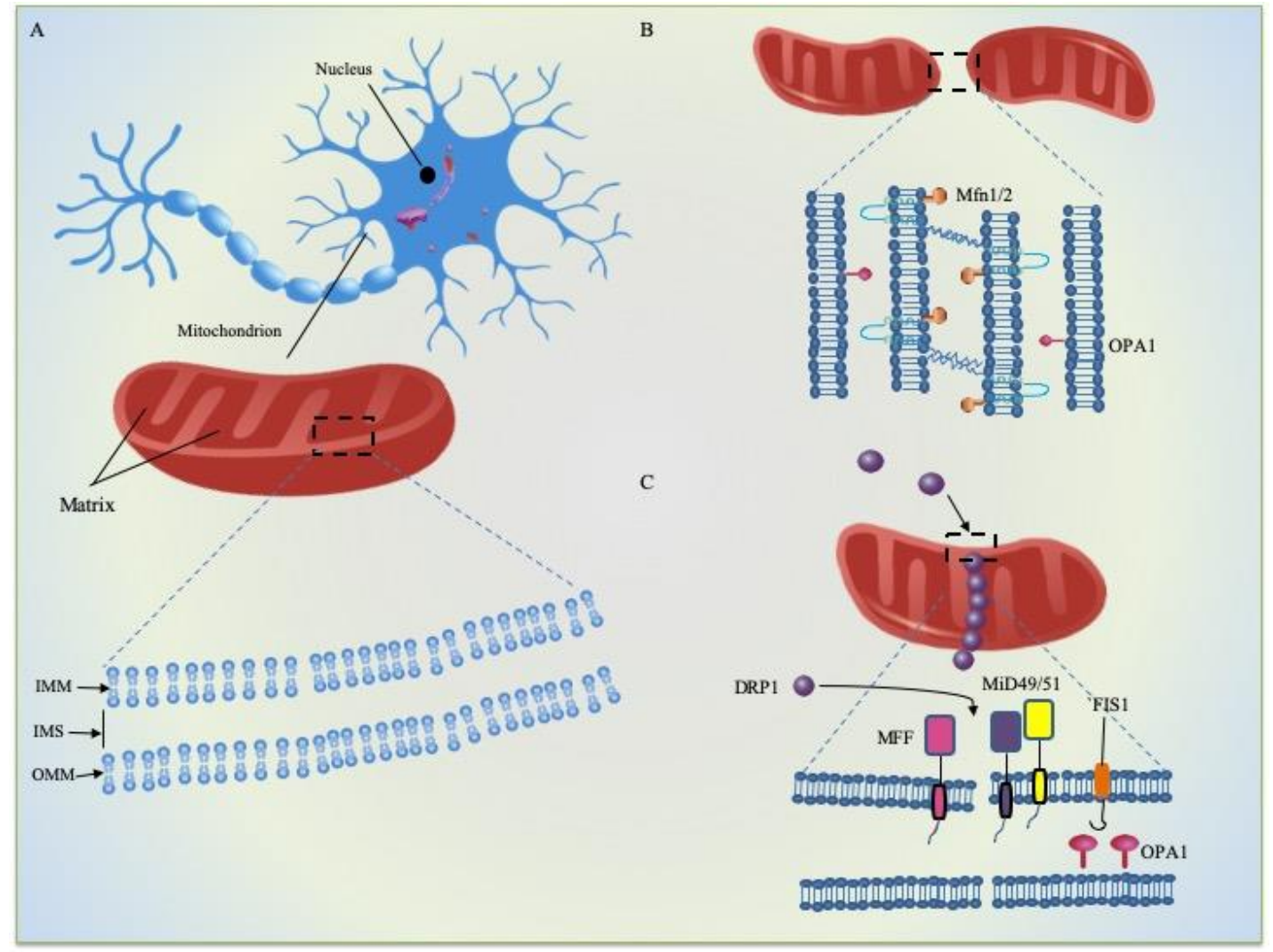

Figure 1. Mitochondrial cell biology. (A) structure of mitochondrion and general features of mitochondrial dynamics (B) fusion (C) fission. 
In addition to its most essential functions of energy production, ROS production, and $\mathrm{Ca}^{2+}$ homeostasis, mitochondria also play a role in apoptosis [23]. Cell apoptosis can trigger by the release of cell death signaling molecules from the mitochondria to the cytoplasm through the permeabilization of OMM [24]. This mitochondrion-involved apoptosis modulated by three groups of $\mathrm{Bcl}-2$ family proteins: Bcl-2-like proteins, $\mathrm{Bax} / \mathrm{Bak}$ proteins, and $\mathrm{BH} 3$ proteins [25]. The OMM permeabilization is caused by the channel within the OMM formed by Bax/Bak proteins. Through this channel, the caspase protein, a key signaling molecule, is released into the cytoplasm. After activation by cytochrome C, Smac and Omi, the apoptosome is formed and activated, causing severe cell death [25].

\subsection{Mitochondrial biogenesis, degradation, and their regulations}

Mitochondrial productions show an interaction present between the nuclear and mitochondrial genomes. In the mammalian genome, 37 genes have been defined in mitochondrial DNA (mtDNA. Of these genes, 13 are mRNAs that encode polypeptides for OXPHOS, and the rest aid in the transcription and translation within the organelle, with 22 being tRNAs and 2 being rRNAs [26$31]$. However, the nuclear genome encoded around 1500 kinds of proteins and translated on cytoplasmic ribosomes, where they are eventually imported into mitochondria by the translocase of the inner membrane (TIM) and the outer membrane (TOM) [32]. This dual origin implies that coordinate mitochondria. Phospholipids are either directly synthesized in the organelle or imported from the endoplasmic reticulum membrane after synthesis, along with many cofactors and metals. The OMM has a similar composition to the rest of the cell and contains a pore formed by the $\beta$-barrel protein voltage-dependent anion channel (VDAC) through which interchange happens between the cytosol and the IMS [32]. The IMM greatly enhances its area by infolding into cristae in the shape of gracile sacs and contains a large amount of the phospholipid cardiolipin on the surface. In a sense, the crista is a supporting measure for very useful OXPHOS [19] and has the vast majority proteases. As the first phase of mitochondrial quality control, a mitochondrion can clean low levels of damaged proteins with the aid of intraorganellar proteases and chaperones, for instance, HTRA2 and TRAP1 [33].

Mitochondria continually divide, blend, and alter their size, knitting a dynamic network within the cell, and their movement and turnover in the matrix coordinated by the cytoskeleton [34]. These processes collectively termed as mitochondrial dynamics. In other words, to maintain both of the quality and quantity or meet the needs of cells/tissues, mitochondria go through constant fusion and fission. The latter recognize as one core mitochondrial quality-control pathway [33]. Balanced fusion and fission can shape the final mitochondria to fit mitochondrial metabolism and ensure the removal of other dysfunctional organelles [20]. Mitochondrial degradation happens in response to cellular damage and nutrient excess and has documented in cancer, obesity, and cardiovascular and neuromuscular disorders $[26,28$, 35-39]. The autophagic clearance of mitochondria facilitated to adapt the mitochondrial activities to satisfy the physiological needs[40].

\section{Mitophagy- mitochondrial autophagy}

\subsection{Autophagy and autophagy flux}

Macroautophagy, commonly known as autophagy, is a major intracytoplasmic pathway for the elimination of damaged organelles and protein aggregates, recycles cellular biomaterial. It is a conserved lysosomal degradative process whereby obsolete cellular constituents are delivered by double-membrane vesicles (called autophagosomes) to the lysosome for degradation. The dynamic process of autophagy presented with the term 'autophagic flux.' It mainly includes autophagosome formation, maturation, fusion with lysosomes, and subsequent decomposition and release of the remaining molecules into the cytosol [41, 42]. In $\mathrm{AD}, \mathrm{A} \beta$, one of its pathological hallmarks, may be degraded by autophagy or even be reduced by the upregulation of autophagy in many in vivo and in vitro systems [43-46]. Additionally, aberrant Tau induces an increase in the number of autophagosomes and contributes to toxicity in $\mathrm{AD}$ [47, 48]. The in vitro experiments and the mouse model showed that Tau binds lysosomal membranes to change its permeability [49, 50]. Perez et al. indicated that defective lysosomal membrane integrity contributes to $\mathrm{AD}$ onset, which is independent of Tau or $\mathrm{A} \beta$ pathology [51]. In a word, several studies demonstrated that autophagic flux defects are closely correlated to the pathogenesis of $\mathrm{AD}$ [52-54], and the overall investigations predict that modulations of autophagy are therapeutic opportunities for $\mathrm{AD}[55,56]$. However, the autophagy pathway is involved with multiple steps and different modes of regulation which makes it complicated.

\subsection{Mitophagy cell biology and detection}

Compared with nuclear DNA, disruption of mitochondrial dynamics results in reasonably high ROS, which causes more oxidative damage to mtDNA as there is no protection of associated histones and other chromatin proteins. These damaged mitochondria are selectively 
marked, elongated by phagophores to form a mature mitophagosome, and fused with lysosomes where they degrade as autolysosomes. This macroautophagy process, namely mitophagy, is one of the mitochondrial quality control pathways used to guarantee basal mitochondrial turnover [57-59]. In addition to the ROS inducer, mitophagy also can be induced by some physiological conditions, including the maturation of erythrocytes and the development of fertilized oocytes [60, 61]mitochondrial dynamics and mitophagy, cells can have stringent quality control mechanisms to maintain a healthy mitochondrial population [62].

All types of mitophagy are mainly modulated by the (PTEN-induced putative kinase 1) Pink1-Parkin pathway, whose primary target is the mitochondrion devoid of the membrane potential $(\Delta \Psi \mathrm{m})$ [63]. In normal circumstances, Pink1 is predominately expressed on the IMM, translocated to the cytosol, and digested by the proteasome. However, when mitochondria lose biological functions, the Pink-Parkin pathway is immediately activated. Instead of being degraded by the proteasome, Pink translocated to the OMM, which results in its accumulation on the OMM [64-66]. Subsequently, Pink stabilizes on OMM and promotes the recruitment of Parkin, whose E3 ligase activity launched. Parkin then ubiquitinates several components on the OMM to format poly-ubiquitin chains. After subsequent phosphorylation by Pink1, the poly-ubiquitin chains release 'clean me' signals for autophagic machinery. As a result, dysfunctional mitochondria are recognized and bound by adaptor proteins (such as p62, OPTN, NDP52) through the poly-ubiquitin chains followed by the elongation, maturation, and enclosure of the double membraned phagophore [67]. The autophagosome formation is initiated by binding with LC3, and finally, the matured autophagosome fuses with the acidic lysosome for the degradation and recycling of the engulfed mitochondria. Moreover, independent of Parkin, autophagosomes can be recruited to mitochondria via direct interaction with LC3 by increasing the expression of FUNDC1 and NIX in mammalian cells $[68,69]$. Some ubiquitin ligases can target depolarized mitochondria for mitophagy, such as SMURF1 [70, 71]. Other molecular mechanisms of mitophagy have been extensively studied [16, 72, 73]. Collectively, the major mitophagy pathways include the PHB2 pathway, the cardiolipin pathway, the NBR1 pathway, the Tax1 binding protein 1 (TAXIBP1) pathway, the OPTN pathway, the BNIP3 pathway, the BCL2L13 pathway, the FKBP8 pathway, the AMBRA1 pathway, and the NDP52 pathway. A detailed description of these pathways has summarized in recent reviews [72-74]. Remarkably, Lu et al. found a new class of adaptors, namely CUET proteins, can bind ubiquitylated substrates in yeast, implying the potential variety of the complements in the above pathways [75]. Emerging evidence suggests that mitochondrial dynamics affect the homeostasis of mitophagy. As mitochondrial fusion and fission have implicated in many of the classical mitochondrion-associated cellular pathways such as calcium signaling, apoptosis, and the cell cycle, it generally believes that mitochondrial fission facilitates mitophagy as smaller mitochondria are easier for autophagic engulfment $[34,76]$. Thus, it is critical to correctly measuring mitophagy. There are several versatile methods to quantify mitophagy in human cells, C. elegans (e.g., Rosella and DCT-1/LGG-1 strains), flies (e.g., mito-QC and mito-Keima strains). Besides, the mito-QC and mito-Keima stains in mice are also available, enabling a temporospatial evaluation of mitophagy [73, 77-81].

Interestingly, Paasch et al. proposed that nonfunctional mitochondrial proteins modestly induced by failed mitochondrial import can mark by SUMO (small ubiquitin-like modifier). Therefore, SUMOylation can serve as intraorganellar protein quality control [82]. Since mitophagy is a constant, dynamic and sophisticated cellular process, a combination of different mitophagy detection approaches, including cross-species evaluation, will improve the accuracy of measuring mitophagy and lead to a better understanding of mitophagy in the physiology of neurons, potentially contributing valuable information to the effort of advancing the therapy of neurodegenerative diseases.

\subsection{Compromised mitophagy in AD}

Although the exact mechanism is not precise, emerging findings suggest that impaired mitophagy contributes to neuronal dysfunction and cognitive decline by trigging $\mathrm{A} \beta$ and $\mathrm{p}$-Tau accumulation in AD pathophysiology [16, $28,83]$. These protein aggregations can produce adverse effects on mitochondrial functions, such as a disruption to the membrane potential resulting in less ATP production. This disruption also can change the permeabilization of the OMM by opening mitochondrial permeability transition pore (mPTP) [23]. Moreover, intramitochondrial $A \beta$ has been demonstrated to interplay with $\mathrm{ABAD}$ ( $\mathrm{A} \beta$ binding alcohol dehydrogenase) than to generate ROS [33]. Partly due to these processes, the neurons in $\mathrm{AD}$ patients experience mitochondrial dysfunction, which causes a bioenergetic deficit early and promotes the $A \beta$ and p-Tau pathologies [16]. Mitophagy predominantly regulates mitochondrial dynamics and the timely clearance of dysfunctional mitochondria that is necessary for the maintenance of synaptic plasticity, neuronal function and neuronal survival. Mitophagy in neurons is essential to prevent neuronal death and pathogenic brain aging via targeting the superfluous or 
dysfunctional mitochondria by lysosomes [72, 84, 85]. Cumulative evidence reveals that compromised mitophagy contributes to aging and neurodegeneration observed in models of premature aging disease and $\mathrm{AD}$ [16, 77, 85-88]. Mitophagy deficits and accumulation of mitochondria detected in $\mathrm{AD}$ human post-mortem tissue as well as reduced phosphorylation of mitophagy initiation proteins (ULK1, TBK1) and elevated levels of mitochondrial membrane proteins (COXIV, TOMM20) $[77,88]$. Increasing experiments from C. elegans, murine and human cell lines overexpressing WT and mutant tau implicate impaired mitophagy, which leads to the accumulation of dysfunctional mitochondria and the impairment of cognitive deficits $[77,86,88]$.

Impaired autophagic flux related to mitochondria is another contributor to the neurodegeneration of $\mathrm{AD}$. The defects may arise from any of the critical processes mentioned above. Unfortunately, the mechanisms underlying the deficiencies in AD are not fundamentally understood. As mentioned earlier in this review, autophagic flux consistently and efficiently initiated by autophagosomes, also called autophagic vacuoles (AVs) followed by formation, maturation, fusion, and digestion within lysosomes. Induced autophagy causes the AV aggregations in $\mathrm{AD}$, impairment of digestion/breakdown steps, and a high rate of autophagosome formation companying with inefficient fusion with lysosomes [89]. Boland et al. proved that blocking the clearance of autophagosomes in cultured neurons by restraining lysosomal proteolysis results in rapid and marked AV accumulation [43]. Nevertheless, the autophagosomes accumulation in the $\mathrm{AD}$ brain does not mean that autophagy initiation is upregulated [90, 91].

On the contrary, one of the essential initiators, Beclin-1 cleaved by caspase three enzyme is low expressed in AD patients [92]. In an APP transgenic mouse model, the deletion of Beclin-1 stops autophagy and accelerates A $\beta$ accumulation [90]. In addition to the defects in the initiation process, genetic or functional alterations may exist in autophagosome maturation, formation, or clearance processes [89, 93, 94]. Taking the mutations in presenilin-1 as an example, the primary defect in lysosome acidification and proteolysis causes pathogenic protein accumulation in AD.

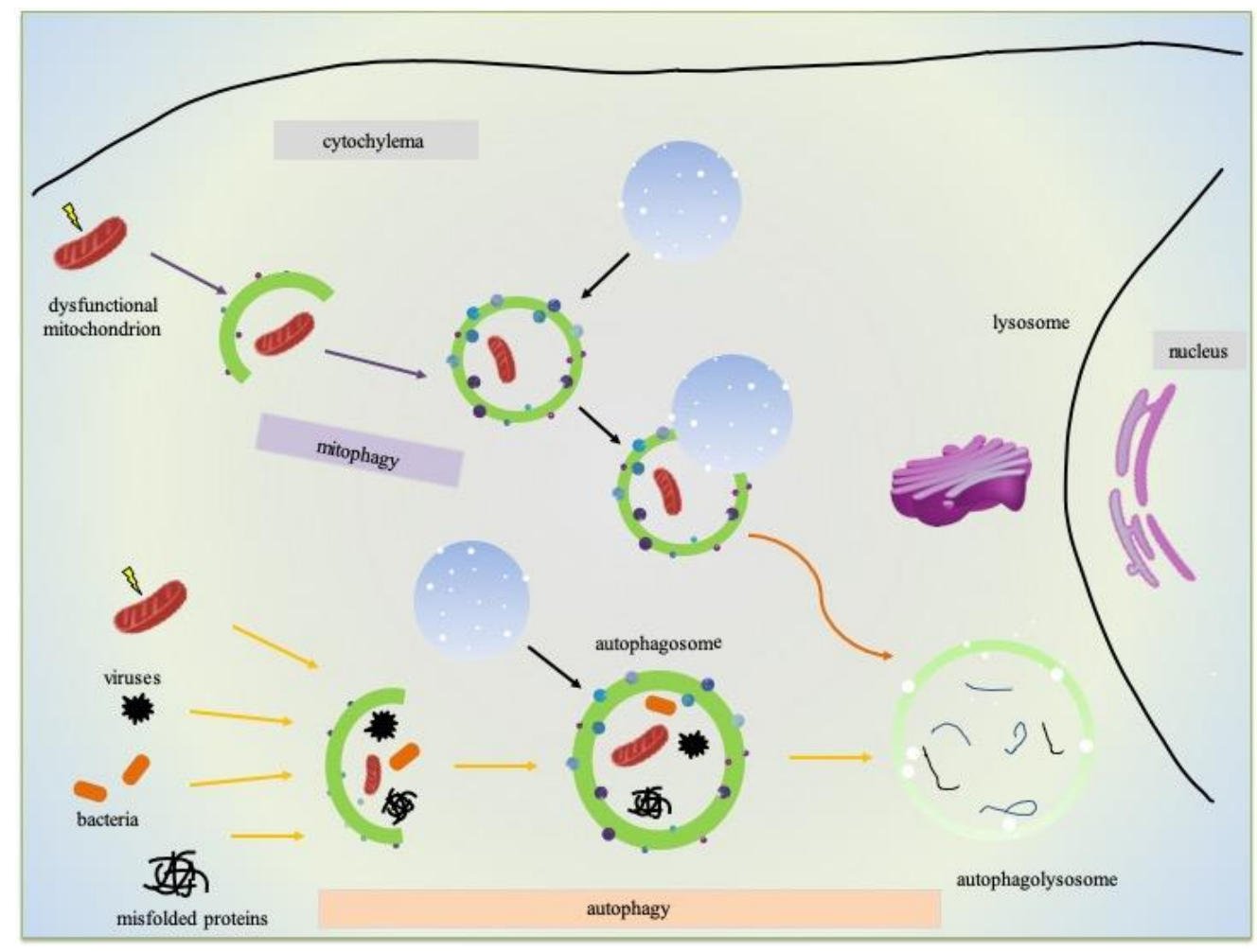

Figure 2. Overview of autophagy/mitophagy in neurons.

The neurodegeneration of $\mathrm{AD}$ directly linked to autophagic flux, and there are several methods developed to identify the status of autophagic fix [42]. The most straightforward approach in experiments for monitoring autophagy is Atg8/LC3 detection and quantification [95, 96]. Autophagic flux perceives by LC3-II turnover with 
the aid of western blot in the absence and presence of lysosomal degradation inhibitors, such as E64d, pepstatin $\mathrm{A}, \mathrm{NH}_{4} \mathrm{Cl}$, bafilomycin $\mathrm{A} 1$ and chloroquine. The signal of LC3-II increases in the presence of one of the above inhibitors when the autophagic flux is occurring as the transition of LC3-II is blocked [97-99]. The other two methods are assays for degradation of SQSTM1/p62 and long-lived proteins, for details, please refer to $[42,100]$. (Fig. 2)

\subsection{Impaired proteostasis related to mitophagy}

The phenomena of protein misfolding and aggregation presented in many kinds of neurodegenerative disease studies. Presently, each of them characterized neurodegenerative diseases with at least one pivotal protein misfolded, which serves as a clinical biomarker. Usually, this protein repeatedly generated and aggregated, along with the disease exacerbation [101]. In $\mathrm{AD}$, the most significant manifestation of misfolded proteins is cerebral plaques. P-Tau proteins and $A \beta$ peptides separately form neurofibrillary tangles (NFTs) and $A \beta$ plaques. Reasonably, the cellular proteostasis in ADrelated to mitophagy is easily impaired, including those involved in mitochondrial biogenesis (PGC-1 $\alpha$ ) [102], mitochondrial responses to oxidative [103] and bioenergetic challenges (SIRT3) [104], mitochondrial fission and fusion (Drp1) [105]. Lysosomes are the protease pool in cells that play the role of disintegrating the ultimately damaged and dysfunctional molecules. Nevertheless, the experiments on cell culture and AD animal models illustrated that mitochondrial concomitants emerged from the excessive fission as a result of lysosomal dysfunction $[106,107]$.

Table 1. Summary of different pathways and genes/proteins involved in autophagy/mitophagy.

\begin{tabular}{|lcc|}
\hline \multicolumn{1}{|c}{ Pathways } & Genes/Proteins & Refs \\
\hline $\begin{array}{l}\text { The PINK1/Parkin- } \\
\text { dependent pathway }\end{array}$ & $\begin{array}{c}\text { PINK1, Parkin, USP8, } \\
\text { USP30, AMBRA1, Bcl2, } \\
\text { FUNDC1, MUL1, Nix, } \\
\text { ATG5, LC3 }\end{array}$ & $\begin{array}{l}{[14,} \\
\text { The }\end{array}$ \\
\hline $\begin{array}{l}\text { The Parkin- } \\
\text { independent } \\
\text { pathway }\end{array}$ & PINK1 & {$[120]$} \\
\hline $\begin{array}{l}\text { The Reticulocyte } \\
\text { pathway }\end{array}$ & Nix, LC3 \\
\hline $\begin{array}{l}\text { The Zygote pathway } \\
\text { The MDVs pathway }\end{array}$ & PINK1, Parkin, LC3 & {$[60]$} \\
\hline The mTOR pathway & ULK1, Atg1, Atg13, Akt, & {$[45]$} \\
\hline
\end{tabular}

In mammals, about 20 proteins are involved in mitophagy, including Drp1, mitofusin, PGC-1 $\alpha$, SIRT, ULK1, BNIP3L/NIX, TBK1, PINK1, and Parkin (see Table 1). Several studies have declared that increased levels of Drp1 in the brains of AD mice and patients were detected while some others have conflicting results [108, 109]. Analyses of postmortem brain tissues of AD patients and age-matched controls have uncovered reduced expression of genes associated with mitochondrial biogenesis, including TFAM, PGC- $1 \alpha$, and NRF2. The mitochondrial SIRT3 and nuclear SIRT1 are NAD ${ }^{+}$ dependent deacetylases, which may inhibit AD through the modulation of many cellular pathways. The reduction of these two proteins may link to neurodegenerative diseases. Studies in the parietal cortex of AD patients shown that reduced SIRT1 expression is closely associated with the accumulation of Tau tangles and $A \beta$ plaques [110]. Notably, SIRT1 can upregulate PGC-1 $\alpha$ and participate in the mitophagy induction through the activation and deacetylation of the major autophagy proteins (ATG8/LC3, ATG5, ATG7) and the upregulation of the mitophagy proteins (NIX/BNIP3L, LC3) [85, 87]. Martine and her colleagues provided a mechanism for cell death with the axis of PAPR-1_NAD ${ }^{+}$SIRT1_PGC-1 $\alpha$, which links nuclear DNA damage to mitochondrial homeostasis. They explained that activated PARP-1 (the enzyme poly(ADP-ribose) polymerase1) contributes to $\mathrm{AD}$ by the accumulation of ADP-ribose polymers and energy crisis $[84,111]$. A steep reduction of $\mathrm{NAD}^{+}$levels can induce through the increase of PARP-1 activity, with the consequence of mitochondrial impairment [112]. Genetically, mutations in genes encoding the proteins outlined above contribute to the etiology of $\mathrm{AD}[113$, 114]. Furthermore, the modifications in core autophagy genes also facilitate AD incidence. An E122D ATG5 mutation weakens the combination of ATG5 and ATG12, resulting in reduced autophagy flux and decreased autophagosome formation [115]. Another gene is WDR45, which codes for the protein WIPI4. In mammalian cells, the WIPI4 proteins bridge PI3P production and LC3 lipidation to assist autophagosome maturation $[116,117]$. Together, the well-defined roles in mitophagy demonstrate that defects in proteins related to mitochondrial quality control and homeostasis are intimately involved in the pathology of AD [118].

\section{Autophagy/mitophagy therapeutics for AD}

\section{1 Autophagy upregulation as therapy for $A D$}

Plentiful previous studies suggest the performance of autophagic dysfunction in the pathogenesis of neurodegenerative diseases, including $\mathrm{AD}$, because of aggregated proteins [125-128]. These 'toxins' are mainly 
degraded by both the ubiquitin-proteasome pathway and the autophagy pathway as substrates [129]. However, the former path cannot vigorously work as only unfolded substrates can pass through the proteasome barrel [130]. Double-membrane-bounded autophagosome besieges them into the center to start autophagy. The lysosome then fuses with the circinate autophagosome to create auto phagolysosome, in which multiple proteases degrade the protein complex. Numerous studies provide proof of the modulation of autophagy as a good therapeutic approach for neurodegenerative disease. The in vitro work examining the effect of autophagy upregulation on the clearance of aggregation-prone proteins caused by polyQ and polyA expansions, mutant tau, and ataxin-3 [131, 132] and mutant $\alpha$-synuclein $[133,134]$ has suggested reductions in both of associated cell death and intracytoplasmic aggregates. Autophagy protects against both pro-apoptotic[135, 136] and pro-necrotic insults [137]. The protective effect from autophagy induction in cell models has successfully translated into a range of animal models. However, the experiments of Zhou et al. on C. elegans and mice lacking sgk-1 (serum/ glucocorticoid regulated kinase-1) illustrated that a high level of mPTP opening induced by elevated autophagy unexpectedly shortens their lifespan [138], implying side effects maybe occur while enhancing autophagy.

Table 2. Pharmacological agents potentially stimulate autophagy/mitophagy.

\begin{tabular}{|c|c|c|c|}
\hline Agents & Study model & Effect & Refs \\
\hline 2,4-Dinitrophenol (DNP) & animal model & stimulate autophagy & [139] \\
\hline rapamycin & $\mathrm{AD}$ mouse & reduce $\mathrm{A} \beta$ pathology & [45] \\
\hline spermidine & $\begin{array}{l}\text { human and yeast cells; } \\
\text { nematodes }\end{array}$ & induce autophagy independent of SIRT1 & [140] \\
\hline urolithin A & C. elegans; mouse & $\begin{array}{l}\text { induce mitophagy, prolong lifespan; increase muscle } \\
\text { function }\end{array}$ & [141] \\
\hline antibiotic & the mt-Keima mouse & provide a method to analyze mitophagy alterations & {$[81]$} \\
\hline 2-deoxyglucose & AD female mouse & $\begin{array}{l}\text { stimulate ketogenesis and induce mild bioenergetic } \\
\text { stress; } \\
\text { enhance mitochondrial function; } \\
\text { stimulate autophagy and clearance of } A \beta\end{array}$ & {$[142-149]$} \\
\hline $\begin{array}{l}\text { nicotinamide } \\
\text { mononucleotide (NMN) }\end{array}$ & $\begin{array}{l}\text { Mouse model of fatty liver } \\
\text { disease; AD mouse }\end{array}$ & increase $\mathrm{NAD}^{+}$pool & {$[150-154]$} \\
\hline $\begin{array}{l}\text { 5-aminoimidazole-4- } \\
\text { carboxamide } \\
\text { ribonucleotide (AICAR) }\end{array}$ & myopathy mouse & activates AMPK to acts on PGC-1 & {$[155-157]$} \\
\hline actinonin & Caenorhabditis elegans & reverse memory impairment & {$[77]$} \\
\hline mdivi1 & excitotoxic mouse & enhance DRP1 activity & [158-164] \\
\hline
\end{tabular}

Numerous autophagy-modulating agents developed to treat $\mathrm{AD}$, including the mechanistic target of rapamycin (mTOR)-dependent and mTOR-independent autophagyincluding agents (see Table 2) [165]. The master metabolic regulator mTOR can formulate two different functional complexes. The researcher believes that mTOR complex 1 (mTORC1) inhibits autophagy, while mTORC2 may differentially regulate autophagy/ mitophagy under different conditions [138, 166]. Rapamycin was the first drug to be identified as an autophagy inducer[167, 168]. Although the mTOR pathway is involved in a wide range of cellular functions, the therapeutic effects of rapamycin in models of neurodegenerative disease are predominantly autophagymediated $[132,166]$. The restricted absorption of rapamycin has driven the development of many rapalogs such as everolimus (RAD001), temsirolimus (CCI-779), and ridaforolimus (AP23573). To date, it is these rapalogs that have investigated due to their potential therapeutic value in the treatment of neurodegenerative diseases. ATP-competitive mTOR inhibitors are newly developed mTOR inhibitors [169]. Stimulation of the AMPK pathway upregulates autophagy as an mTOR-dependent manner [170]. Metformin is an AMPK activator with therapeutic potential in neurodegenerative disease [171]. There is no doubt that further testing of such compounds in different $\mathrm{AD}$ animal models are necessary for their implementation in $\mathrm{AD}$ patient iPSC-derived neurons and glial cells. What is noticeable is that autophagy inducers are unlikely to be pancreatically linked for many neurodegenerative diseases [172], which, for instance, can be seen by short-term fasting [173]. 


\section{2 Enhancing mitophagy as a novel therapeutic strategy for $A D$}

Accumulating studies suggest that dysfunctional mitochondria are mainly due to impaired mitophagy in neurons in $\mathrm{AD}$ [83, 174-177]. The 'vicious cycle' hypothesis proposed that loss-of-function mitophagy and $\mathrm{A} \beta$ and $\mathrm{p}$-Tau, the biomarkers in $\mathrm{AD}$ pathophysiology, strongly influence each other [103, 114]. Moreover, the 'vicious cycle' experiments state that $A \beta$-dependent neuronal hyperactivity supports circuit dysfunction in the early stages of $\mathrm{AD}$ [178]. Recently, Fang and his colleagues successfully stimulated mitophagy and reversed memory impairment using $\mathrm{NAD}^{+}$ supplementation, urolithin $A$ and action in both $A \beta$ and tau Caenorhabditis elegans models [77]. The stimulation of mitophagy affected the PINK1-, PDR1- or DCT1dependent pathways. In human neurons derived from the hippocampus of $\mathrm{AD}$ patients and in $\mathrm{AD}$ animal models, enhanced mitophagy can even diminish insoluble $A \beta$ and prevent cognitive impairment in $\mathrm{AD}$ mouse model through the suppression of neuroinflammation and microglial phagocytosis of $A \beta$ plaques [77]. These findings predict that enhancing mitophagy could be a novel approach to delay or even treat AD [179, 180]. To this end, plentiful pharmacological agents have been examined in preclinical studies [181-183].

Research over the last few decades has extended understanding of nicotinamide adenine dinucleotide $\left(\mathrm{NAD}^{+}\right)$from a vital redox carrier and energy provider to a critical signaling molecule that is involved in the regulation of a multitude of fundamental cellular processes. To date, $\mathrm{NAD}^{+}$plays vital roles in gene expression, DNA repair, calcium signaling, cell cycle regulation, mitochondrial homeostasis and neuronal maintenance and plasticity [184]. NAD ${ }^{+}$is also a substrate for several families of regulatory proteins, such as poly (ADP-ribose) polymerases (PARPs), CD38/CD73, Sirtuins, and SARM1 [184, 185]. At the molecular level, the $\mathrm{NAD}^{+}$-dependent signaling events differ from hydride transfer since these $\mathrm{NAD}^{+}$-consuming enzymes cleave $\mathrm{NAD}^{+}$into an ADP-ribosyl moiety and nicotinamide. Therefore, non-redox functions of $\mathrm{NAD}^{+}$require continuous biosynthesis of the dinucleotide.

As an essential cellular metabolite, $\mathrm{NAD}^{+}$exists in all living cells, including brain cells, where it plays fundamental roles in neuroplasticity and cellular stress resistance [186]. Because neurons consume relatively large amounts of energy, they are susceptible to decreased $\mathrm{NAD}^{+}$levels as well as the impairment of ATP production $[16,85]$. Furthermore, $\mathrm{NAD}^{+}$affects neuronal health and survival through regulation of the balance between mitochondrial biogenesis and mitophagy, which are controlled by the NAD ${ }^{+} /$SIRT1-PGC-1 $\alpha$ pathway and the
DAF-16/FOXO3 pathway $[85,87]$. Decreased NAD ${ }^{+}$ levels can compromise mitophagy and trigger the accumulation of misfolded proteins leading to neuronal death [87, 187]. Cellular $\mathrm{NAD}^{+}$levels are affected by several $\mathrm{NAD}^{+}$-consuming enzymes which have links to $\mathrm{AD}[188]$.

$\mathrm{NAD}^{+}$levels decline in the $\mathrm{AD}$ brain in a few possible ways. PARP1 is an enzyme that responds to DNA strand breaks by catalyzing poly ADP-ribosylation (PARylation) of target proteins using $\mathrm{NAD}^{+}$as a cofactor $[85,188,189]$. While PARP1 was localizing the nucleus, it is now known to also localize to mitochondria in cells under stress where it can PARylate electron transport chain proteins. Levels of PARP1 activity are increased, and PARylated proteins accumulate in brain tissue samples from vulnerable brain regions of AD patients [190]. Therefore, oxidative stress is a likely trigger for PARP1 activation in $\mathrm{AD}$, which may occur both upstream and downstream of $A \beta$ accumulation. $\mathrm{CD} 38$ is a multifunctional enzyme that catalyzes the synthesis and hydrolysis of cyclic ADP-ribose (cADPR) from NAD ${ }^{+}$to ADP-ribose and mediates $\mathrm{Ca}^{2+}$ release from the endoplasmic reticulum. Importantly, PARP1 and CD38 activity may lead to decreased $\mathrm{NAD}^{+}$levels and thus lower sirtuin activity. Treatment of neural cells with a PARP1 inhibitor can protect them against mitochondrial dysfunction and cell death caused by A $\beta$ [191]. APP/PS1 double mutant transgenic mice that lack CD38 exhibit reduced levels of $A B$ in their brains and improved learning and memory [192], consistent with $\mathrm{NAD}^{+}$ depletion in the promotion of amyloidogenesis in this mouse model of AD. Many researchers suggest that $\mathrm{NAD}^{+}$deficiency in $\mathrm{AD}$, possibly caused by PARP1 activation due to increased oxidative stress-mediated DNA damage, leads to decreased mitophagy, decreased sirtuin activity, and mitochondrial dysfunction.

\section{3 Other therapeutic strategies for $A D$}

In addition to pharmacological agents, lifestyle interventions also can stimulate mitophagy to protect the mitochondrial population. It has been evaluated in animal models and even in MCI (mild cognitive impairment) or AD patients. Experiments using rodents show that fasting can reduce ROS and inflammation, optimize energy metabolism, and enhance autophagy [173, 193]. For example, fasting for two days can make GFC-LC3 transgenic mice have more autophagosomes in the neurons of the cerebral cortex. Studies of human subjects and animal models demonstrate that regular exercise provides robust beneficial effects, which in turn can reduce the risk of AD [194]. Vaynman et al. showed that by upregulating mitochondrial uncoupling protein 2 (UCP2) levels in the hippocampus, exercise could lower 
ROS and active autophagy. Caloric restriction (CR) also can enhance mitochondrial function. On the one hand, CR can decrease ROS and reduce oxidative DNA damage; on the other hand, CR can induce the expression of many sirtuins, especially SIRT1. Its overexpression can extend the life span and improve the syndromes of AD [195]. In sum, the enhanced mitophagy can reclaim the dysfunctional mitochondria to maintain high-quality mitochondrial homeostasis in neurons.

\section{Conclusions}

In this review, we have delineated mitochondrial biology, the average and defective autophagy and mitophagy in $\mathrm{AD}$, highlighting their pathogenesis and corresponding therapeutic strategies. In $\mathrm{AD}$, mitochondrial dysfunction and the bioenergetic deficit contribute to the $A \beta$ and $p$ Tau pathologies; in turn, these two pathologies promote mitochondrial defects. As a consequence, a fundamental characteristic of $\mathrm{AD}$ is the impairment of mitochondria, which has been ascertained in both sporadic and familiar types of samples as well as in animal models. As stated above, pharmacological agents, fasting, physical exercise, and caloric restriction can reverse this impairment. The main target of these methods is to enhance autophagy and mitophagy. Mitophagy plays a fundamental role in mitochondrial quality control and homeostasis, and the pathological consequences of its misregulation demonstrate its importance. However, the exact positions of mitophagy in $\mathrm{AD}$ etiology are still unclear as multiple steps are affected. Cells regulate mitochondrial degradation not only through control of the mitophagy machinery but also through delicate tuning of mitochondrial fusion and fission $[34,76]$. It remains to see whether other cellular processes linked with mitochondria also have a role to play in mitophagy regulation. Further understanding of the mechanisms involved in mitochondrial quality control will hopefully hold therapeutic potential for $\mathrm{AD}$.

Here we would like to recommend $\mathrm{NAD}^{+}$to implement further research in drug discovery for $\mathrm{AD}$. The importance of the regulatory roles of $\mathrm{NAD}^{+}$has established in many excellent studies. While impressive progress has made regarding the mechanisms of $\mathrm{NAD}^{+}$dependent inhibition of AD pathology and the restoration of cognitive function, some critical questions remain unanswered. For example, cellular $\mathrm{NAD}^{+}$biosynthesis and consumption compartmentalized in the cell, but how these organellar $\mathrm{NAD}^{+}$pools are established and maintained in neurons and glial cells, including astrocytes and microglia, remains unknown. Furthermore, what are the differences between different $\mathrm{NAD}^{+}$precursors, NMN, NR, nicotinic acid, and nicotinamide, in treating $\mathrm{AD}$ ? The pharmacokinetics and potential toxicity data of
$\mathrm{NAD}^{+}$augmentation strategies in $\mathrm{AD}$ patients need to obtain in the clinic.AD might be not only a brain disorder but also a systemic disease with widespread abnormalities beyond the brain. Thus, systemic factors might interact with brain-related elements to modify the $\mathrm{AD}$ process. $\mathrm{AD}$ diagnosis and treatment should have a corresponding focus not only on pathological changes in the brain but also on peripheral abnormalities, which vary among individuals. Identifying these peripheral abnormalities might offer new opportunities for diagnosis of early $\mathrm{AD}$ and lead to the design of specific treatment strategies for individuals with $\mathrm{AD}$ at different stages.

\section{Future perspectives}

In the past 20 years, most of the drugs tested in the clinic for $\mathrm{AD}$ have targeted the $\mathrm{A} \beta$ accumulation; however, none of these anti-A $\beta$ therapies overcome the central problem [196]. Today, a promising alternative option for $\mathrm{AD}$ therapeutics is to maintain mitochondrial homeostasis by enhancing autophagy and stimulating mitophagy. Dysfunctional mitophagy can increase $A \beta$ and Tau pathologies, while aggregating $A \beta$ can impair neuronal mitophagy in reverse. These outcomes indicate pivotal roles for mitophagy dysfunction, both upstream and downstream of $A \beta$ and Tau pathways [16]. In all, different theories such as "amyloid plaques, NFT, mitochondrial dysfunction, neuroinflammation, comprised autophagy et al." result in AD etiologies that interact with each other [197]. The 'Chicken and egg' relationships between different hallmarks of AD need to establish, and specific therapy should direct to target the reason for the neuronal insult and not the host response. Meanwhile, we can seek some clues from the treatment of other diseases like cancers, diabetes and rheumatoid arthritis.

\section{Acknowledgments}

We acknowledge the valuable work of the many investigators whose published articles we were unable to cite owing to space limitations. The grants from Jiangsu University (19JDG039) supported this work.

\section{References}

[1] Patterson C. 2018. World Alzheimer Report 2018- The state of the art of dementia research: New frontiers: Alzheimer's Disease International (ADI), London.

[2] Bachman DL, Wolf PA, Linn R, Knoefel JE, Cobb J, Belanger A, et al. (1992). Prevalence of dementia and probable senile dementia of the Alzheimer type in the Framingham Study. Neurology, 42:5.

[3] Bachman DL, Wolf PA, Linn RT, Knoefel JE, Cobb JL, Belanger AJ, et al. (1993). Incidence of dementia and probable Alzheimer's disease in a general population: 
The Framingham Study. Neurology, 43:515-519.

[4] Beard CM, Lane AW, O'Fallon WM, Riggs BL, Melton LJ (1994). Comparison of Respondents and Nonrespondents in an Osteoporosis Study. Ann Epidemiol, 4:398-403.

[5] Nussbaum JM, Seward ME, Bloom GS (2013). Alzheimer disease: a tale of two prions. Prion, 7:14-19.

[6] Serrano-Pozo A, Frosch MP, Masliah E, Hyman BT (2011). Neuropathological alterations in Alzheimer disease. Cold Spring Harb Perspect Med, 1:a006189.

[7] Heneka MT, Carson MJ, Khoury JE, Landreth GE, Brosseron F, Feinstein DL, et al. (2015). Neuroinflammation in Alzheimer's disease. The Lancet Neurology, 14:388-405.

[8] Spires-Jones TL, Hyman BT (2014). The intersection of amyloid beta and tau at synapses in Alzheimer's disease. Neuron, 82:756-771.

[9] Qureshi YH, Patel VM, Berman DE, Kothiya MJ, Neufeld JL, Vardarajan B, et al. (2018). An Alzheimer's disease-linked loss-of-function CLN5 variant impairs cathepsin D maturation, consistent with a retromer trafficking defect. Molecular and cellular biology, 38:e0011-00018.

[10] Cheng R, Tang M, Martinez I, Ayodele T, Baez P, Reyes-Dumeyer D, et al. (2018). Linkage analysis of multiplex Caribbean Hispanic families loaded for unexplained early-onset cases identifies novel Alzheimer's disease loci. Alzheimers Dement (Amst), 10:554-562.

[11] Zhang Y, Kumar A, Tezel JB, Zhou Y (2016). Imaging Evidence for Cerebral Hyperperfusion Syndrome after Intravenous Tissue Plasminogen Activator for Acute Ischemic Stroke. Case Rep Neurol Med, 2016:8725494.

[12] Kunkle BW, Grenier-Boley B, Sims R, Bis JC, Damotte $\mathrm{V}$, Naj AC, et al. (2019). Genetic meta-analysis of diagnosed Alzheimer's disease identifies new risk loci and implicates Abeta, tau, immunity and lipid processing. Nat Genet, 51:414-430.

[13] Bondi MW, Edmonds EC, Salmon DP (2017). Alzheimer's Disease: Past, Present, and Future. Journal of the International Neuropsychological Society, 23:818-831.

[14] Bachurin SO, Bovina EV, Ustyugov AA (2017). Drugs in Clinical Trials for Alzheimer's Disease: The Major Trends. Med Res Rev, 37:1186-1225.

[15] Canter RG, Penney J, Tsai L-H (2016). The road to restoring neural circuits for the treatment of Alzheimer's disease. Nature, 539:187-196.

[16] Kerr JS, Adriaanse BA, Greig NH, Mattson MP, Cader MZ, Bohr VA, et al. (2017). Mitophagy and Alzheimer's Disease- Cellular and Molecular Mechanisms. Trends in Neurosciences, 40:16.

[17] Wang Y, Xu E, Musich PR, Lin F (2019). Mitochondrial dysfunction in neurodegenerative diseases and the potential countermeasure. CNS Neurosci Ther, 25:816824.

[18] Castellani R, Hirai K, Aliev G, Drew KL, Nunomura A, Takeda A, et al. (2002). Role of mitochondrial dysfunction in Alzheimer's disease. J Neurosci Res, 70:357-360.
[19] Wai T, Langer T (2016). Mitochondrial Dynamics and Metabolic Regulation. Trends Endocrinol Metab, 27:105-117.

[20] Youle RJ, van der Bliek AM (2012). Mitochondrial fission, fusion, and stress. Science, 337:1062-1065.

[21] ME B, VI D, EN M, VP S (1998). Membrane potential generation coupled to oxidation of external NADH in liver mitochondria. FEBS Lett, 435:269-274.

[22] Hoffmann A, Dimroth P (1991). The electrochemical proton potential of Bacillus alcalophilus. Eur J Biochem, 201:467-473.

[23] Cowan K, Anichtchik O, Luo S (2019). Mitochondrial integrity in neurodegeneration. CNS Neurosci Ther, 25:825-836.

[24] Tait SW, Green DR (2010). Mitochondria and cell death: outer membrane permeabilization and beyond. Nat Rev Mol Cell Biol, 11:621-632.

[25] Youle RJ, Strasser A (2008). The BCL-2 protein family: opposing activities that mediate cell death. Nat Rev Mol Cell Biol, 9:47-59.

[26] Nunnari J, Suomalainen A (2012). Mitochondria: in sickness and in health. Cell, 148:1145-1159.

[27] Mehta MM, Weinberg SE, Chandel NS (2017). Mitochondrial control of immunity: beyond ATP. Nat Rev Immunol, 17:608-620.

[28] Suomalainen A, Battersby BJ (2018). Mitochondrial diseases: the contribution of organelle stress responses to pathology. Nat Rev Mol Cell Biol, 19:77-92.

[29] Ni HM, Williams JA, Ding WX (2015). Mitochondrial dynamics and mitochondrial quality control. Redox Biol, 4:6-13.

[30] Wallace DC, Fan W, Procaccio V (2010). Mitochondrial energetics and therapeutics. Annu Rev Pathol, 5:297348.

[31] Koopman WJH, Willems PHGM, Smeitink JAM (2012). Monogenic mitochondrial disorders. The new England journal of medicine, 366:1132-1141.

[32] Smith RA, Hartley RC, Cocheme HM, Murphy MP (2012). Mitochondrial pharmacology. Trends Pharmacol Sci, 33:341-352.

[33] de Castro IP, Martins LM, Tufi R (2010). Mitochondrial quality control and neurological disease: an emerging connection. Expert Rev Mol Med, 12:e12.

[34] Chen H, Chan DC (2009). Mitochondrial dynamicsfusion, fission, movement, and mitophagy-in neurodegenerative diseases. Human Molecular Genetics, 18:R169-R176.

[35] Murphy E, Bers D, Rizzuto R (2009). Mitochondria: from basic biology to cardiovascular disease. J Mol Cell Cardiol, 46:765-766.

[36] Hassani A, Horvath R, Chinnery PF (2010). Mitochondrial myopathies: developments in treatment. Curr Opin Neurol, 23:459-465.

[37] DeBerardinis RJ, Chandel NS (2016). Fundamentals of cancer metabolism. Science Advances, 2:e1600200.

[38] Hanahan D, Weinberg RA (2011). Hallmarks of cancer: the next generation. Cell, 144:646-674.

[39] Ward PS, Thompson CB (2012). Metabolic reprogramming: a cancer hallmark even warburg did not anticipate. Cancer Cell, 21:297-308. 
[40] Elfawy HA, Das B (2019). Crosstalk between mitochondrial dysfunction, oxidative stress, and age related neurodegenerative disease: Etiologies and therapeutic strategies. Life Sciences, 218:165-184.

[41] Zhang XJ, Chen S, Huang KX, Le WD (2013). Why should autophagic flux be assessed? Acta Pharmacol Sin, 34:595-599.

[42] Klionsky DJ, Abdelmohsen K, Abe A, Abedin MJ, Abeliovich H, Acevedo Arozena A, et al. (2016). Guidelines for the use and interpretation of assays for monitoring autophagy (3rd edition). Autophagy, 12:1222.

[43] Boland B, Kumar A, Lee S, Platt FM, Wegiel J, Yu WH, et al. (2008). Autophagy Induction and Autophagosome Clearance in Neurons: Relationship to Autophagic Pathology in Alzheimer's Disease. Journal of Neuroscience, 28:6926-6937.

[44] Vingtdeux V, Chandakkar P, Zhao H, d'Abramo C, Davies P, Marambaud P (2011). Novel synthetic smallmolecule activators of AMPK as enhancers of autophagy and amyloid- $\beta$ peptide degradation. The FASEB Journal, 25:219-231.

[45] Spilman P, Podlutskaya N, Hart MJ, Debnath J, Gorostiza O, Bredesen D, et al. (2010). Inhibition of mTOR by rapamycin abolishes cognitive deficits and reduces amyloid-beta levels in a mouse model of Alzheimer's disease. PLoS One, 5:e9979.

[46] Tian Y, Bustos V, Flajolet M, Greengard P (2011). A small-molecule enhancer of autophagy decreases levels of $A \beta$ and APP-CTFviaAtg5-dependent autophagy pathway. The FASEB Journal, 25:1934-1942.

[47] Butzlaff M, Hannan SB, Karsten P, Lenz S, Ng J, Vossfeldt H, et al. (2015). Impaired retrograde transport by the Dynein/Dynactin complex contributes to Tauinduced toxicity. Hum Mol Genet, 24:3623-3637.

[48] Majid T, Ali YO, Venkitaramani DV, Jang MK, Lu HC, Pautler RG (2014). In vivo axonal transport deficits in a mouse model of fronto-temporal dementia. Neuroimage Clin, 4:711-717.

[49] Collin L, Bohrmann B, Gopfert U, Oroszlan-Szovik K, Ozmen L, Gruninger F (2014). Neuronal uptake of $\mathrm{tau} / \mathrm{pS} 422$ antibody and reduced progression of tau pathology in a mouse model of Alzheimer's disease. Brain, 137:2834-2846.

[50] Wang Y, Martinez-Vicente M, Kruger U, Kaushik S, Wong E, Mandelkow EM, et al. (2009). Tau fragmentation, aggregation and clearance: the dual role of lysosomal processing. Hum Mol Genet, 18:41534170.

[51] Perez SE, He B, Nadeem M, Wuu J, Ginsberg SD, Ikonomovic MD, et al. (2015). Hippocampal Endosomal, Lysosomal, and Autophagic Dysregulation in Mild Cognitive Impairment- Correlation With AA and Tau Pathology. Journal of Neuropathology \& Experimental Neurology, 74:345-358.

[52] Vidal RL, Matus S, Bargsted L, Hetz C (2014). Targeting autophagy in neurodegenerative diseases. Trends Pharmacol Sci, 35:583-591.

[53] Wong E, Cuervo AM (2010). Autophagy gone awry in neurodegenerative diseases. Nat Neurosci, 13:805-811.
[54] Liang JH, Jia JP (2014). Dysfunctional autophagy in Alzheimer's disease: pathogenic roles and therapeutic implications. Neurosci Bull, 30:308-316.

[55] Schneider JL, Cuervo AM (2014). Autophagy and human disease: emerging themes. Curr Opin Genet Dev, 26:16-23.

[56] Rubinsztein DC, Gestwicki JE, Murphy LO, Klionsky DJ (2007). Potential therapeutic applications of autophagy. Nat Rev Drug Discov, 6:304-312.

[57] Kim I, Rodriguez-Enriquez S, Lemasters JJ (2007). Selective degradation of mitochondria by mitophagy. Arch Biochem Biophys, 462:245-253.

[58] Rodriguez-Enriquez S, Kim I, Currin RT, Lemasters JJ (2006). Tracker Dyes to Probe Mitochondrial Autophagy (Mitophagy) in Rat Hepatocytes. Autophagy, 2:39-46.

[59] Kissova I, Deffieu M, Manon S, Camougrand N (2004). Uth1p is involved in the autophagic degradation of mitochondria. J Biol Chem, 279:39068-39074.

[60] Sandoval H, Thiagarajan P, Dasgupta SK, Schumacher A, Prchal JT, Chen M, et al. (2008). Essential role for Nix in autophagic maturation of erythroid cells. Nature, 454:232-235

[61] Sato M, Sato K (2011). Degradation of Paternal Mitochondria by Fertilization-Triggered Autophagy in C. elegans Embryos. Science, 334:1141-1144.

[62] Anzell AR, Maizy R, Przyklenk K, Sanderson TH (2018). Mitochondrial Quality Control and Disease: Insights into Ischemia-Reperfusion Injury. Mol Neurobiol, 55:2547-2564.

[63] Narendra DP, Youle RJ (2011). Targeting mitochondrial dysfunction: role for PINK1 and Parkin in mitochondrial quality control. Antioxid Redox Signal, 14:1929-1938.

[64] Narendra D, Kane LA, Hauser DN, Fearnley IM, Youle $\mathrm{RJ}$ (2010). p62/SQSTM1 is required for Parkin-induced mitochondrial clustering but not mitophagy; VDAC1 is dispensable for both. Autophagy, 6:1090-1106.

[65] Jin SM, Lazarou M, Wang C, Kane LA, Narendra DP, Youle RJ (2010). Mitochondrial membrane potential regulates PINK1 import and proteolytic destabilization by PARL. J Cell Biol, 191:933-942.

[66] Valente EM, Abou-Sleiman PM, Caputo V, Muqit MM, Harvey K, Gispert S, et al. (2004). Hereditary earlyonset Parkinson's disease caused by mutations in PINK1. Science, 304:1158-1160.

[67] Geisler S, Holmstrom KM, Skujat D, Fiesel FC, Rothfuss OC, Kahle PJ, et al. (2010). PINK1/Parkinmediated mitophagy is dependent on VDAC1 and p62/SQSTM1. Nat Cell Biol, 12:119-131.

[68] Liu L, Feng D, Chen G, Chen M, Zheng Q, Song P, et al. (2012). Mitochondrial outer-membrane protein FUNDC1 mediates hypoxia-induced mitophagy in mammalian cells. Nat Cell Biol, 14:177-185.

[69] Novak I, Kirkin V, McEwan DG, Zhang J, Wild P, Rozenknop A, et al. (2010). Nix is a selective autophagy receptor for mitochondrial clearance. EMBO Rep, 11:45-51.

[70] Fu M, St-Pierre P, Shankar J, Wang PT, Joshi B, Nabi IR (2013). Regulation of mitophagy by the Gp78 E3 
ubiquitin ligase. Mol Biol Cell, 24:1153-1162.

[71] Ding WX, Yin XM (2012). Mitophagy: mechanisms, pathophysiological roles, and analysis. Biol Chem, 393:547-564.

[72] Fivenson EM, Lautrup S, Sun N, Scheibye-Knudsen M, Stevnsner T, Nilsen H, et al. (2017). Mitophagy in neurodegeneration and aging. Neurochemistry International, 109:202-209.

[73] Palikaras K, Lionaki E, Tavernarakis N (2018). Mechanisms of mitophagy in cellular homeostasis, physiology and pathology. Nature Cell Biology, 20:1013-1022.

[74] Pickrell Alicia M, Youle Richard J (2015). The Roles of PINK1, Parkin, and Mitochondrial Fidelity in Parkinson's Disease. Neuron, 85:257-273.

[75] Hoppe T, Branzei D (2017). Stefan Jentsch (19552016)-Maestro of the ubiquitin family. EMBO J, 36:12.

[76] Burman JL, Pickles S, Wang C, Sekine S, Vargas JNS, Zhang Z, et al. (2017). Mitochondrial fission facilitates the selective mitophagy of protein aggregates. The Journal of Cell Biology, 216:3231-3247.

[77] Fang EF, Hou Y, Palikaras K, Adriaanse BA, Kerr JS, Yang B, et al. (2019). Mitophagy inhibits amyloid- $\beta$ and tau pathology and reverses cognitive deficits in models of Alzheimer's disease. Nature Neuroscience, 22:401-412.

[78] Fang EF, Palikaras K, Sun N, Fivenson EM, Spangler $\mathrm{RD}$, Kerr JS, et al. (2017). In Vitro and In Vivo Detection of Mitophagy in Human Cells, C. Elegans, and Mice. Journal of Visualized Experiments.

[79] Lee JJ, Sanchez-Martinez A, Zarate AM, Benincá C, Mayor U, Clague MJ, et al. (2018). Basal mitophagy is widespread in Drosophila but minimally affected by loss of Pink1 or parkin. The Journal of Cell Biology, 217:1613-1622.

[80] McWilliams TG, Prescott AR, Montava-Garriga L, Ball G, Singh F, Barini E, et al. (2018). Basal Mitophagy Occurs Independently of PINK1 in Mouse Tissues of High Metabolic Demand. Cell Metabolism, 27:439449.e435.

[81] Sun N, Yun J, Liu J, Malide D, Liu C, Rovira Ilsa I, et al. (2015). Measuring In Vivo Mitophagy. Molecular Cell, 60:685-696.

[82] Dannheisig DP, Beck E, Calzia E, Walther P, Behrends C, Pfister AS (2019). Loss of Peter Pan (PPAN) Affects Mitochondrial Homeostasis and Autophagic Flux. Cells, 8.

[83] Moreira PI, Carvalho C, Zhu X, Smith MA, Perry G (2010). Mitochondrial dysfunction is a trigger of Alzheimer's disease pathophysiology. Biochimica et Biophysica Acta (BBA) - Molecular Basis of Disease, 1802:2-10.

[84] Fang EF, Scheibye-Knudsen M, Chua KF, Mattson MP, Croteau DL, Bohr VA (2016). Nuclear DNA damage signalling to mitochondria in ageing. Nature Reviews Molecular Cell Biology, 17:308-321.

[85] Fang Evandro F, Scheibye-Knudsen M, Brace Lear E, Kassahun H, SenGupta T, Nilsen H, et al. (2014). Defective Mitophagy in XPA via PARP-1
Hyperactivation and NAD+/SIRT1 Reduction. Cell, 157:882-896.

[86] Cummins C, Seale M, Macente A, Certini D, Mastropaolo E, Viola IM, et al. (2018). A separated vortex ring underlies the flight of the dandelion. Nature, 562:414-418.

[87] Fang EF, Kassahun H, Croteau DL, Scheibye-Knudsen M, Marosi K, Lu H, et al. (2016). NAD+ Replenishment Improves Lifespan and Healthspan in Ataxia Telangiectasia Models via Mitophagy and DNA Repair. Cell Metabolism, 24:566-581.

[88] Hu Y, Li X-C, Wang Z-h, Luo Y, Zhang X, Liu X-P, et al. (2016). Tau accumulation impairs mitophagy via increasing mitochondrial membrane potential and reducing mitochondrial Parkin. Oncotarget, 7:17356.

[89] Barnett A, Brewer GJ (2011). Autophagy in aging and Alzheimer's disease: pathologic or protective? J Alzheimers Dis, 25:385-394.

[90] Pickford F, Masliah E, Britschgi M, Lucin K, Narasimhan R, Jaeger PA, et al. (2008). The autophagyrelated protein beclin 1 shows reduced expression in early Alzheimer disease and regulates amyloid beta accumulation in mice. J Clin Invest, 118:2190-2199.

[91] Liang XH, Jackson S, Seaman M, Brown K, Kempkes B, Hibshoosh H, et al. (1999). Induction of autophagy and inhibition of tumorigenesis by beclin 1 . Nature, 402:672-676.

[92] Rohn TT, Wirawan E, Brown RJ, Harris JR, Masliah E, Vandenabeele P (2011). Depletion of Beclin-1 due to proteolytic cleavage by caspases in the Alzheimer's disease brain. Neurobiol Dis, 43:68-78.

[93] Ravikumar B, Acevedo-Arozena A, Imarisio S, Berger Z, Vacher C, O'Kane CJ, et al. (2005). Dynein mutations impair autophagic clearance of aggregateprone proteins. Nat Genet, 37:771-776.

[94] Zhang Y, Xu M, Xia M, Li X, Boini KM, Wang M, et al. (2014). Defective autophagosome trafficking contributes to impaired autophagic flux in coronary arterial myocytes lacking CD38 gene. Cardiovasc Res, 102:68-78.

[95] Ju JS, Varadhachary AS, Miller SE, Weihl CC (2010). Quantitation of "autophagic flux" in mature skeletal muscle. Autophagy, 6:929-935.

[96] Klionsky DJ, Elazar Z, Seglen PO, Rubinsztein DC (2008). Does bafilomycin A1 block the fusion of autophagosomes with lysosomes? Autophagy, 4:849850.

[97] Tanida I, Minematsu-Ikeguchi N, Ueno T, Kominami E (2005). Lysosomal Turnover, but Not a Cellular Level, of Endogenous LC3 is a Marker for Autophagy. Autophagy., 1:84-91.

[98] Kabeya Y, Mizushima N, Ueno T, Yamamoto A, Kirisako T, Noda T, et al. (2000). LC3, a mammalian homologue of yeast Apg8p, is localized in autophagosome membranes after processing. EMBO J, 19:5720-5728.

[99] Oh SH, Choi YB, Kim JH, Weihl CC, Ju JS (2017). Quantification of autophagy flux using LC3 ELISA. Anal Biochem, 530:57-67.

[100] Pankiv S, Clausen TH, Lamark T, Brech A, Bruun JA, 
Outzen H, et al. (2007). p62/SQSTM1 binds directly to Atg8/LC3 to facilitate degradation of ubiquitinated protein aggregates by autophagy. J Biol Chem, 282:24131-24145.

[101] Gandhi J, Antonelli AC, Afridi A, Vatsia S, Joshi G, Romanov V, et al. (2019). Protein misfolding and aggregation in neurodegenerative diseases: a review of pathogeneses, novel detection strategies, and potential therapeutics. Reviews in the Neurosciences, 30:339358.

[102] Cheng A, Wan R, Yang JL, Kamimura N, Son TG, Ouyang X, et al. (2012). Involvement of PGC-1alpha in the formation and maintenance of neuronal dendritic spines. Nat Commun, 3:1250.

[103] Mattson MP, Gleichmann M, Cheng A (2008). Mitochondria in Neuroplasticity and Neurological Disorders. Neuron, 60:748-766.

[104] Cheng A, Yang Y, Zhou Y, Maharana C, Lu D, Peng W, et al. (2016). Mitochondrial SIRT3 Mediates Adaptive Responses of Neurons to Exercise and Metabolic and Excitatory Challenges. Cell Metab, 23:128-142.

[105] Donlea JM, Ramanan N, Shaw PJ (2009). SNitrosylation of Drp1 Mediates $\beta$-Amyloid-Related Mitochondrial Fission and Neuronal Injury. Science, 324:105-108.

[106] DuBoff B, Feany M, Gotz J (2013). Why size matters balancing mitochondrial dynamics in Alzheimer's disease. Trends Neurosci, 36:325-335.

[107] Nixon RA (2013). The role of autophagy in neurodegenerative disease. Nat Med, 19:983-997.

[108] Wang X, Su B, Fujioka H, Zhu X (2008). Dynamin-like protein 1 reduction underlies mitochondrial morphology and distribution abnormalities in fibroblasts from sporadic Alzheimer's disease patients. Am J Pathol, 173:470-482.

[109] Cho D-H, Nakamura T, Fang J, Cieplak P, Godzik A, $\mathrm{Gu}$ Z, et al. (2009). S-Nitrosylation of Drp1 Mediates b-Amyloid-Related Mitochondrial Fission and Neuronal Injury. Science, 324:102-105.

[110] Julien C, Tremblay C, Emond V, Lebbadi M, Salem N, Jr., Bennett DA, et al. (2009). Sirtuin 1 reduction parallels the accumulation of tau in Alzheimer disease. J Neuropathol Exp Neurol, 68:48-58.

[111] Martire S, Mosca L, d'Erme M (2015). PARP-1 involvement in neurodegeneration: A focus on Alzheimer's and Parkinson's diseases. Mechanisms of Ageing and Development, 146-148:53-64.

[112] Alano CC, Garnier P, Ying W, Higashi Y, Kauppinen TM, Swanson RA (2010). NAD+ depletion is necessary and sufficient for poly(ADP-ribose) polymerase-1mediated neuronal death. J Neurosci, 30:2967-2978.

[113] Onyango IG, Dennis J, Khan SM (2016). Mitochondrial Dysfunction in Alzheimer's Disease and the Rationale for Bioenergetics Based Therapies. Aging Dis, 7:201214.

[114] Cai Q, Tammineni P (2016). Alterations in Mitochondrial Quality Control in Alzheimer's Disease. Frontiers in Cellular Neuroscience, 10:17.

[115] Kim M, Sandford E, Gatica D, Qiu Y, Liu X, Zheng Y, et al. (2016). Mutation in ATG5 reduces autophagy and leads to ataxia with developmental delay. Elife, 5.

[116] Proikas-Cezanne T, Waddell S, Gaugel A, Frickey T, Lupas A, Nordheim A (2004). WIPI-1alpha (WIPI49), a member of the novel 7-bladed WIPI protein family, is aberrantly expressed in human cancer and is linked to starvation-induced autophagy. Oncogene, 23:93149325.

[117] Lamb CA, Yoshimori T, Tooze SA (2013). The autophagosome: origins unknown, biogenesis complex. Nat Rev Mol Cell Biol, 14:759-774.

[118] Ye X, Sun X, Starovoytov V, Cai Q (2015). Parkinmediated mitophagy in mutant hAPP neurons and Alzheimer's disease patient brains. Hum Mol Genet, 24:2938-2951.

[119] Youle RJ, Narendra DP (2010). Mechanisms of mitophagy. Nature Reviews Molecular Cell Biology, 12:9-14.

[120] Lazarou M, Sliter DA, Kane LA, Sarraf SA, Wang C, Burman JL, et al. (2015). The ubiquitin kinase PINK1 recruits autophagy receptors to induce mitophagy. Nature, 524:309-314.

[121] Zhou Q, Li H, Li H, Nakagawa A, Lin JLJ, Lee E-S, et al. (2016). Mitochondrial endonuclease G mediates breakdown of paternal mitochondria upon fertilization. Science, 353:394-399.

[122] Song WH, Yi YJ, Sutovsky M, Meyers S, Sutovsky P (2016). Autophagy and ubiquitin-proteasome system contribute to sperm mitophagy after mammalian fertilization. Proc Natl Acad Sci U S A, 113:E52615270.

[123] Rojansky R, Cha MY, Chan DC (2016). Elimination of paternal mitochondria in mouse embryos occurs through autophagic degradation dependent on PARKIN and MUL1. Elife, 5.

[124] Sugiura A, McLelland GL, Fon EA, McBride HM (2014). A new pathway for mitochondrial quality control: mitochondrial-derived vesicles. EMBO J, 33:2142-2156.

[125] Taylor JP, Hardy J, Fischbeck KH (2002). Toxic proteins in neurodegenerative disease. Science, 296:1991-1995.

[126] Ross CA, Poirier MA (2004). Protein aggregation and neurodegenerative disease. Nat Med, 10 Suppl:S10-17.

[127] Ross CA, Poirier MA (2005). What is the role of protein aggregation in neurodegeneration. Nature reviews Molecular cell biology, 6 .

[128] Nixon RA, Yang DS (2011). Autophagy failure in Alzheimer's disease--locating the primary defect. Neurobiol Dis, 43:38-45.

[129] Rubinsztein DC (2006). The roles of intracellular protein-degradation pathways in neurodegeneration. Nature, 443:780-786.

[130] Verhoef LGGC, Lindsten K, Masucci MG, Dantuma NP (2002). Aggregate formation inhibits proteasomal degradation of polyglutamine proteins. Hum Mol Genet, 11:2689-2700.

[131] Berger Z, Ravikumar B, Menzies FM, Oroz LG, Underwood BR, Pangalos MN, et al. (2006). Rapamycin alleviates toxicity of different aggregateprone proteins. Hum Mol Genet, 15:433-442. 
[132] Ravikumar B, Duden R, Rubinsztein DC (2002). Aggregate-prone proteins with polyglutamine and polyalanine expansions are degraded by autophagy. Human Molecular Genetics, 11:11.

[133] Spencer B, Potkar R, Trejo M, Rockenstein E, Patrick C, Gindi R, et al. (2009). Beclin 1 gene transfer activates autophagy and ameliorates the neurodegenerative pathology in alpha-synuclein models of Parkinson's and Lewy body diseases. J Neurosci, 29:13578-13588.

[134] Webb JL, Ravikumar B, Atkins J, Skepper JN, Rubinsztein DC (2003). $\alpha$-Synuclein Is Degraded by Both Autophagy and the Proteasome. Journal of Biological Chemistry, 278:25009-25013.

[135] Boya P, Gonza'lez-Polo R-A, Casares N, Perfettini J-L, Dessen P, Larochette N, et al. (2005). Inhibition of Macroautophagy Triggers Apoptosis. Molecular and Cellular Biology, 25:16.

[136] Ravikumar B, Berger Z, Vacher C, O'Kane CJ, Rubinsztein DC (2006). Rapamycin pre-treatment protects against apoptosis. Hum Mol Genet, 15:12091216.

[137] Wu Y-T, Tan H-L, Huang Q, Kim Y-S, Pan N, Ong W$\mathrm{Y}$, et al. (2008). Autophagy plays a protective role during zVAD-induced necrotic cell death. Autophagy, 4:457-466.

[138] Zhou B, Kreuzer J, Kumsta C, Wu L, Kamer KJ, Cedillo L, et al. (2019). Mitochondrial Permeability Uncouples Elevated Autophagy and Lifespan Extension. Cell, 177:299-314.e216.

[139] Geisler JG, Marosi K, Halpern J, Mattson MP (2017). DNP, mitochondrial uncoupling, and neuroprotection: A little dab'll do ya. Alzheimers Dement, 13:582-591.

[140] Morselli E, Marino G, Bennetzen MV, Eisenberg T, Megalou E, Schroeder S, et al. (2011). Spermidine and resveratrol induce autophagy by distinct pathways converging on the acetylproteome. J Cell Biol, 192:615629.

[141] Ryu D, Mouchiroud L, Andreux PA, Katsyuba E, Moullan N, Nicolet-Dit-Felix AA, et al. (2016). Urolithin A induces mitophagy and prolongs lifespan in C. elegans and increases muscle function in rodents. Nat Med, 22:879-888.

[142] Duan W, Mattson MP (1999). Dietary Restriction and 2-Deoxyglucose Administration Improve Behavioral Outcome and Reduce Degeneration of Dopaminergic Neurons in Models of Parkinson's Disease. J Neurosci Res., 57:195-206.

[143] Yao J, Chen S, Mao Z, Cadenas E, Brinton RD (2011). 2-Deoxy-D-glucose treatment induces ketogenesis, sustains mitochondrial function, and reduces pathology in female mouse model of Alzheimer's disease. PLoS One, 6:e21788.

[144] Dodiya HB, Kuntz T, Shaik SM, Baufeld C, Leibowitz J, Zhang X, et al. (2019). Sex-specific effects of microbiome perturbations on cerebral Abeta amyloidosis and microglia phenotypes. J Exp Med, 216:1542-1560

[145] Halbach JL, Wang AW, Hawisher D, Cauvi DM, Lizardo RE, Rosas J, et al. (2017). Why Antibiotic
Treatment Is Not Enough for Sepsis Resolution- an Evaluation in an Experimental Animal Model. Infect Immun, 85

[146] Thompson JM, Saini V, Ashbaugh AG, Miller RJ, Ordonez AA, Ortines RV, et al. (2017). Oral-Only Linezolid-Rifampin Is Highly Effective Compared with Other Antibiotics for Periprosthetic Joint Infection: Study of a Mouse Model. J Bone Joint Surg Am, 99:656-665.

[147] Minter MR, Zhang C, Leone V, Ringus DL, Zhang X, Oyler-Castrillo P, et al. (2016). Antibiotic-induced perturbations in gut microbial diversity influences neuro-inflammation and amyloidosis in a murine model of Alzheimer's disease. Sci Rep, 6:30028.

[148] Chiaravalli M, Rowe I, Mannella V, Quilici G, Canu T, Bianchi V, et al. (2016). 2-Deoxy-d-Glucose Ameliorates PKD Progression. J Am Soc Nephrol, 27:1958-1969.

[149] Tolomeo D, Micotti E, Serra SC, Chappell M, Snellman A, Forloni G (2018). Chemical exchange saturation transfer MRI shows low cerebral 2-deoxy-D-glucose uptake in a model of Alzheimer's Disease. Sci Rep, 8:9576.

[150] Wagner GR, Bhatt DP, O'Connell TM, Thompson JW, Dubois LG, Backos DS, et al. (2017). A Class of Reactive Acyl-CoA Species Reveals the Nonenzymatic Origins of Protein Acylation. Cell Metab, 25:823-837 e828.

[151] Moehle EA, Shen K, Dillin A (2019). Mitochondrial proteostasis in the context of cellular and organismal health and aging. J Biol Chem, 294:5396-5407.

[152] Tarantini S, Valcarcel-Ares MN, Toth P, Yabluchanskiy A, Tucsek Z, Kiss T, et al. (2019). Nicotinamide mononucleotide (NMN) supplementation rescues cerebromicrovascular endothelial function and neurovascular coupling responses and improves cognitive function in aged mice. Redox Biol, 24:101192.

[153] Mills KF, Yoshida S, Stein LR, Grozio A, Kubota S, Sasaki Y, et al. (2016). Long-Term Administration of Nicotinamide Mononucleotide Mitigates AgeAssociated Physiological Decline in Mice. Cell Metab, 24:795-806.

[154] Hou Y, Lautrup S, Cordonnier S, Wang Y, Croteau DL, Zavala E, et al. (2018). NAD $(+)$ supplementation normalizes key Alzheimer's features and DNA damage responses in a new AD mouse model with introduced DNA repair deficiency. Proc Natl Acad Sci U S A, 115:E1876-E1885.

[155] Yang SJ, Choi JM, Kim L, Park SE, Rhee EJ, Lee WY, et al. (2014). Nicotinamide improves glucose metabolism and affects the hepatic NAD-sirtuin pathway in a rodent model of obesity and type 2 diabetes. J Nutr Biochem, 25:66-72.

[156] Kingwell K (2019). Turning up mitophagy in Alzheimer disease. Nat Rev Drug Discov.

[157] Nath N, Giri S, Prasad R, Salem ML, Singh AK, Singh I (2005). 5-aminoimidazole-4-carboxamide ribonucleoside: a novel immunomodulator with therapeutic efficacy in experimental autoimmune encephalomyelitis. J Immunol, 175:566-574. 
[158] Scarpulla RC (2011). Metabolic control of mitochondrial biogenesis through the PGC-1 family regulatory network. Biochim Biophys Acta, 1813:12691278.

[159] Enrica A, Marinos D, Sara S, Carlos MT, Salvatore D, Eric SA (1991). Depletion of muscle mitochondrial DNA in AIDS patients with zidovudine-induced myopathy. Lancet, 337:508-510.

[160] Valero T (2014). Mitochondrial biogenesispharmacological approaches. Curr Pharm Des, 20:5507-5509.

[161] Li YH, Xu F, Thome R, Guo MF, Sun ML, Song GB, et al. (2019). Mdivi-1, a mitochondrial fission inhibitor, modulates $\mathrm{T}$ helper cells and suppresses the development of experimental autoimmune encephalomyelitis. J Neuroinflammation, 16:149.

[162] Manczak M, Kandimalla R, Yin X, Reddy PH (2019). Mitochondrial division inhibitor 1 reduces dynaminrelated protein 1 and mitochondrial fission activity. Hum Mol Genet, 28:177-199.

[163] Veeranki S, Tyagi SC (2017). Mdivi-1 induced acute changes in the angiogenic profile after ischemiareperfusion injury in female mice. Physiol Rep, 5.

[164] Reddy PH, Manczak M, Yin X (2017). MitochondriaDivision Inhibitor 1 Protects Against Amyloid-beta induced Mitochondrial Fragmentation and Synaptic Damage in Alzheimer's Disease. J Alzheimers Dis, 58:147-162.

[165] Thellung S, Corsaro A, Nizzari M, Barbieri F, Florio T (2019). Autophagy Activator Drugs: A New Opportunity in Neuroprotection from Misfolded Protein Toxicity. Int J Mol Sci, 20.

[166] Sabatini DM (2017). Twenty-five years of mTOR: Uncovering the link from nutrients to growth. Proceedings of the National Academy of Sciences, 114:11818-11825

[167] Blommaart EFC, Luiken JJFP, Blommaart PJE, Woerkom GMv, Meijer AJ (1995). Phosphorylation of ribosomal protein S6 is inhibitory for autophagy in isolated rat hepatocytes. The Journal of Biological Chemistry, 270:2320-2326.

[168] Wang T, Lao U, Edgar BA (2009). TOR-mediated autophagy regulates cell death in Drosophila neurodegenerative disease. J Cell Biol, 186:703-711.

[169] Benjamin D, Colombi M, Moroni C, Hall MN (2011). Rapamycin passes the torch: a new generation of mTOR inhibitors. Nature Reviews Drug Discovery, 10:868-880.

[170] Meley D, Bauvy C, Houben-Weerts JHPM, Dubbelhuis PF, Helmond MTJ, Codogno P, et al. (2006). AMPactivated Protein Kinase and the Regulation of Autophagic Proteolysis. Journal of Biological Chemistry, 281:34870-34879.

[171] Buzzai M, Jones RG, Amaravadi RK, Lum JJ, DeBerardinis RJ, Zhao F, et al. (2007). Systemic Treatment with the Antidiabetic Drug Metformin Selectively Impairs p53-Deficient Tumor Cell Growth. Cancer Research, 67:6745-6752.

[172] Martini-Stoica H, Xu Y, Ballabio A, Zheng H (2016). The Autophagy-Lysosomal Pathway in
Neurodegeneration: A TFEB Perspective. Trends Neurosci, 39:221-234.

[173] Alirezaei M, Kemball CC, Flynn CT, Wood MR, Whitton JL, Kiosses WB (2010). Short-term fasting induces profound neuronal autophagy. Autophagy, 6:702-710.

[174] Moreira PI, Cardosob SM, Santosc MS, Oliveirab CR (2006). The key role of mitochondria in Alzheimer's disease. J Alzheimers Dis, 9:101-110.

[175] Moreira PI, Santos MS, Oliveira CR (2007). Alzheimer's disease: a lesson from mitochondrial dysfunction. Antioxid Redox Signal, 9:1621-1630.

[176] Moreira PI, Duarte AI, Santos MS, Rego AC, Oliveira CR (2009). An integrative view of the role of oxidative stress, mitochondria and insulin in Alzheimer's disease. J Alzheimers Dis, 16:741-761.

[177] Zhu X, Raina AK, Lee HG, Casadesus G, Smith MA, Perry G (2004). Oxidative stress signaling in Alzheimer's disease. Brain Res, 1000:32-39.

[178] Benedikt Z, Manuel SM, Wei H, Felix U, Hsing-Jung C-E, Matthew FP, et al. (2019). A vicious cycle of $\beta$ amyloid-dependent neuronal hyperactivation. Science, 365:559-565

[179] Sorrentino V, Romani M, Mouchiroud L, Beck JS, Zhang H, D'Amico D, et al. (2017). Enhancing mitochondrial proteostasis reduces amyloid-beta proteotoxicity. Nature, 552:187-193.

[180] R.X. S, S.C. C, C. C, S. C, M.S. S, P.I. M (2011). Mitophagy in Neurodegeneration- An Opportunity for Therapy. Curr Drug Targets, 12:790-799.

[181] Lautrup S, Lou G, Aman Y, Nilsen H, Tao J, Fang EF (2019). Microglial mitophagy mitigates neuroinflammation in Alzheimer's disease. Neurochemistry International, 129.

[182] Camins A, Ettcheto M, Busquets O (2019). Potential preventive disease-modifying pharmacological strategies to delay late onset Alzheimer's disease. Neural Regeneration Research, 14.

[183] Fernandez-Moriano C, Gonzalez-Burgos E, GomezSerranillos MP (2015). Mitochondria-Targeted Protective Compounds in Parkinson's and Alzheimer's Diseases. Oxid Med Cell Longev, 2015:408927.

[184] Fang EF, Lautrup S, Hou Y, Demarest TG, Croteau DL, Mattson MP, et al. (2017). NAD+ in Aging: Molecular Mechanisms and Translational Implications. Trends in Molecular Medicine, 23:899-916.

[185] Verdin E (2015). NAD+ in aging, metabolism, and neurodegeneration. Science, 350:7.

[186] Bonkowski MS, Sinclair DA (2016). Slowing ageing by design: the rise of $\mathrm{NAD}(+)$ and sirtuin-activating compounds. Nat Rev Mol Cell Biol, 17:679-690.

[187] Zhou M, Zhao H, Wang Z, Cheng L, Yang L, Shi H, et al. (2015). Identification and validation of potential prognostic lncRNA biomarkers for predicting survival in patients with multiple myeloma. $\mathrm{J}$ Exp Clin Cancer Res, 34:102.

[188] Canto C, Sauve AA, Bai P (2013). Crosstalk between poly(ADP-ribose) polymerase and sirtuin enzymes. Mol Aspects Med, 34:1168-1201.

[189] Vendin E (2015). NAD+ in aging, metabolism, and 
neurodegeneration. Science, 350:1208-1213.

[190] Strosznajder JB, Czapski GA, Adamczyk A, Strosznajder RP (2012). Poly(ADP-ribose) Polymerase-1 in Amyloid Beta Toxicity and Alzheimer's Disease. Molecular Neurobiology, 46:7884.

[191] Martire S, Fuso A, Mosca L, Forte E, Correani V, Fontana M, et al. (2016). Bioenergetic Impairment in Animal and Cellular Models of Alzheimer's Disease: PARP-1 Inhibition Rescues Metabolic Dysfunctions. J Alzheimers Dis, 54:307-324.

[192] Blacher E, Dadali T, Bespalko A, Haupenthal VJ, Grimm MOW, Hartmann T, et al. (2015). Alzheimer's disease pathology is attenuated in a CD38-deficient mouse model. Annals of Neurology, 78:88-103.

[193] Longo VD, Mattson MP (2014). Fasting: molecular mechanisms and clinical applications. Cell Metab,
19:181-192.

[194] Mattson MP (2015). Lifelong brain health is a lifelong challenge: from evolutionary principles to empirical evidence. Ageing Res Rev, 20:37-45.

[195] Canto C, Auwerx J (2009). Caloric restriction, SIRT1 and longevity. Trends Endocrinol Metab, 20:325-331.

[196] Panza F, Lozupone M, Logroscino G, Imbimbo BP (2019). A critical appraisal of amyloid-beta-targeting therapies for Alzheimer disease. Nat Rev Neurol.

[197] Mattson MP, Arumugam TV (2018). Hallmarks of Brain Aging: Adaptive and Pathological Modification by Metabolic States. Cell Metabolism, 27:1176-1199. 